\title{
Frontline treatment with chemoimmunotherapy for limited- stage ocular adnexal MALT Iymphoma with adverse factors: a phase II study
}

\author{
Sung-Yong Kim ${ }^{1}$, Suk-Woo Yang ${ }^{2}$, Won-Sik Lee ${ }^{3}$, Jae Wook Yang ${ }^{4}$, Sung Yong Oh ${ }^{5}$, \\ Hee Bae Ahn', Deok-Hwan Yang7, Seong Kyu Park ${ }^{8}$, Jee Ho Chang ${ }^{9}$, Hyo Jung \\ $\mathrm{Kim}^{10}$, Min Joung Lee ${ }^{11}$ and Seok-Goo Cho ${ }^{12}$ \\ ${ }^{1}$ Department of Hematology-Oncology, Konkuk University Medical Center, Konkuk University School of Medicine, Seoul, Korea \\ ${ }^{2}$ Department of Ophthalmology and Visual Science, Seoul St. Mary's Hospital, The Catholic University of Korea College of \\ Medicine, Seoul, Korea \\ ${ }^{3}$ Department of Hematology and Oncology, Inje University College of Medicine, Busan Paik Hospital, Busan, Korea \\ ${ }^{4}$ Department of Ophthalmology, Busan Paik Hospital, Inje University, Busan, Korea \\ ${ }^{5}$ Department of Internal Medicine, Dong-A University College of Medicine, Busan, Korea \\ ${ }^{6}$ Department of Ophthalmology, Dong-A University College of Medicine, Busan, Korea \\ ${ }^{7}$ Department of Hematology-Oncology, Chonnam National University Hwasun Hospital, Jeollanamdo, Korea \\ ${ }^{8}$ Department of Internal Medicine, Soonchunhyang University Bucheon Hospital, Soonchunhyang University, Bucheon, Korea \\ ${ }^{9}$ Department of Ophthalmology, Soonchunhyang University Bucheon Hospital, Soonchunhyang University, Bucheon, Korea \\ ${ }^{10}$ Division of Hematology-Oncology, Department of Internal Medicine, College of Medicine, Hallym University, Hallym \\ University Sacred Heart Hospital, Anyang, Korea \\ ${ }^{11}$ Department of Ophthalmology, College of Medicine, Hallym University, Hallym University Sacred Heart Hospital, Anyang, \\ Korea \\ ${ }^{12}$ Department of Hematology, Catholic Blood and Marrow Transplantation Center, Seoul St. Mary's Hospital, The Catholic \\ University of Korea, Seoul, Korea
}

Correspondence to: Seok-Goo Cho, email: chosg@catholic.ac.kr

Keywords: lymphoma, ocular, mucosa associated lymphoid tissue, rituximab, chemoimmunotherapy

Received: March 09, $2017 \quad$ Accepted: June 24, $2017 \quad$ Published: August 02, 2017

Copyright: Kim et al. This is an open-access article distributed under the terms of the Creative Commons Attribution License 3.0 (CC BY 3.0), which permits unrestricted use, distribution, and reproduction in any medium, provided the original author and source are credited.

\section{ABSTRACT}

Background: Radiotherapy is a commonly used treatment for limited-stage ocular adnexal mucosa-associated lymphoid tissue lymphoma (OAML) but showed a substantial relapse risk if the disease involves beyond-conjunctiva or bilateral conjunctivae. Systemic chemoimmunotherapy may be an alternative frontline therapy for the limited disease with those adverse prognostic factors.

Patients and methods: We designed a multicenter, phase II study of the chemoimmunotherapy, rituximab, cyclophosphamide, vincristine, and prednisolone (R-CVP) for the treatment of patients with limited-stage OAML with bilateral or beyond-conjunctival involvement. Thirty-three patients with Ann Arbor stage I OAML with the adverse factors were enrolled. Patients received six cycles of R-CVP followed by two cycles of rituximab therapy.

Results: At the end of treatment, all the enrolled patients had responded. The cumulative complete response achievement was $93.9 \%$ at 2 years. At a median followup of $\mathbf{5 0 . 6}$ months, three patients had progressed. Progression-free survival and overall survival at 4 years was $90.3 \pm 5.3 \%$ and $100 \%$, respectively. 


\section{Conclusions: This phase II study demonstrated durable efficacy of R-CVP chemoimmunotherapy, which has promise as an alternative frontline therapy for the limited-stage OAML patients with adverse prognostic factors. Clinical trial registration: NCT01427114.}

\section{INTRODUCTION}

Ocular adnexal mucosa-associated lymphoid tissue (MALT) lymphoma (OAML) is the most common type of ocular lymphoma and its prevalence is higher in Asia than in western countries [1-3]. OAML is a slowly growing disease and it is generally responsive to radiation therapy. Therefore, patients with limited-stage disease usually undergo radiation therapy, while systemic chemotherapy has been rarely tested as a frontline therapy. However, limited-stage OAML has been reported to have a recurrence rate of $25 \%$ following radiotherapy [4], and the risk of recurrence is higher when the disease involves both eyes or spreads beyond the conjunctiva [5-8]. Previous studies using radiotherapy have demonstrated that the disease recurred predominantly in areas that were not irradiated, mostly the contralateral eye and distant extranodal organs [7, 9-12], so that we reasoned that the relapse rate of nonirradiated areas might be reduced if the limited staged patients with the higher risk factors receive systemic chemoimmunotherapy rather than radiotherapy. In addition, the target volume of irradiation for conjunctiva-only disease is the whole conjunctiva and the risk of cataract can be reduced with lens shielding, but for disease extending beyond the conjunctiva, the whole orbit is generally covered without lens shielding so that the risk of cataract can be considerable [9, 13, 14].

However, only a few trials of systemic chemotherapy or chemoimmunotherapy as a frontline treatment have been conducted in OAML patients with limited-stage disease, because of the rarity of the disease and its responsiveness to radiation therapy [15-17]. Furthermore, most of the prior studies using systemic chemotherapy or chemoimmunotherapy included advanced stage OAML or MALT lymphoma of other sites, and thus it is hard to estimate the efficacy of the frontline systemic therapy in limited-stage OAML. Before rituximab was introduced, a prior retrospective study demonstrated the efficacy of combination chemotherapy, cyclophosphamide, vincristine, and prednisolone (CVP) for the frontline treatment of limited staged OAML [18]. This study is the only previous study of patients with limited-stage OAML who were treated with systemic therapy as a frontline treatment; the complete response (CR) rate for limitedstage OAML with beyond-conjunctival involvement was $67 \%$ and the progression-free survival (PFS) was disappointing. Recently, rituximab has been used for treatment of OAML, but rituximab monotherapy did not demonstrate adequate efficacy, with frequent early relapse and often distant relapse [17]. These observations suggested the need for a combination of rituximab and conventional cytotoxic chemotherapy to ensure long-term disease control. Several prospective trials using rituximabcontaining chemoimmunotherapy were conducted for extranodal marginal zone B cell lymphoma, including the MALT-2008-01 and IELSG-19 trials but these studies enrolled various stage and site MALT lymphoma patients $[15,16,19,20]$.

In this phase II study, a patient with newly diagnosed limited-stage OAML involving bilateral ocular adnexae or spreading beyond the conjunctiva was treated with a combination chemoimmunotherapy with rituximab and CVP, which is generally used in advanced stage, slowly growing CD20 + B cell lymphoma [21]. The present study was designed based on a previous study testing the CVP regimen for limited-stage OAML, and aimed to evaluate the efficacy of this regimen as a frontline therapy for the treatment of limited-stage OAML with adverse factors. This trial was registered with the National Cancer Institute (http://www.clinicaltrials.gov; identifier NCT01427114).

\section{RESULTS}

\section{Patients and disease}

The study patients and disease characteristics are described in Table 1. A total of 33 patients, 21 men and 12 women, were enrolled in this study and all completed the planned treatment. The age of the study patients was 49 years (range, 19-74 years). All study patients had good performance scores and did not have B symptoms. Three patients had elevated levels of lactate dehydrogenase (LDH) while all other study patients had normal levels of $\mathrm{LDH}$.

The anatomic location of disease was the conjunctiva in 12 patients $(36.4 \%)$, the orbit in $13(39.4 \%)$, the eyelid in five $(15.2 \%)$, and the lacrimal duct or gland in three $(9.1 \%)$. Fourteen patients $(42.4 \%)$ had bilateral disease at presentation. According to the Ann Arbor staging at the time of diagnosis, all patients enrolled had stage IE disease, although the eligibility included stage I and II disease. Based on the tumor-node-metastasis (TNM) staging [22], 10 (30.3\%) patients had T1 disease with bilateral involvement and the remaining 23 patients $(69.7 \%)$ had T2 or higher disease.

\section{Response and cumulative incidence of CR achievement}

All study patients responded to the treatment (Table 2). After the third cycle of R-CVP, 15 patients (45.5\%) achieved CR and 18 (54.5\%) partial response 
Table 1: Study patients and disease characteristics

\begin{tabular}{|c|c|}
\hline Characteristics & Number (\%) \\
\hline Total & 33 \\
\hline \multicolumn{2}{|l|}{ Gender } \\
\hline Male & $21(64 \%)$ \\
\hline Female & $12(36 \%)$ \\
\hline Age, median (range) & 49 years $(19-74)$ \\
\hline \multicolumn{2}{|l|}{ Lactic dehydrogenase } \\
\hline Elevated & $3(9 \%)$ \\
\hline Normal & $30(91 \%)$ \\
\hline \multicolumn{2}{|l|}{ B symptom } \\
\hline Yes & $0(0 \%)$ \\
\hline No & $33(100 \%)$ \\
\hline \multicolumn{2}{|l|}{ ECOG Performance Status } \\
\hline $0-1$ & $33(100 \%)$ \\
\hline $2-4$ & $0(0 \%)$ \\
\hline \multicolumn{2}{|l|}{ Location } \\
\hline Orbit & $13(39.4 \%)$ \\
\hline Conjunctiva & $12(36.4 \%)$ \\
\hline Eyelid & $5(15.2 \%)$ \\
\hline Lacrimal gland or duct & $3(9.1 \%)$ \\
\hline \multicolumn{2}{|l|}{ Ann Arbor stage } \\
\hline IE & $33(100 \%)$ \\
\hline IIE & $0(0 \%)$ \\
\hline \multicolumn{2}{|l|}{ TNM stage* } \\
\hline T1N0M0 & $0(0 \%)$ \\
\hline bT1N0M0 & $10(30.3 \%)$ \\
\hline T2N0M0 & $16(48.5 \%)$ \\
\hline bT2N0M0 & $3(9.1 \%)$ \\
\hline T3N0M0 & $2(6.1 \%)$ \\
\hline bT3N0M0 & $1(3 \%)$ \\
\hline T4N0M0 & $1(3 \%)$ \\
\hline bT4N0M0 & $0(0 \%)$ \\
\hline
\end{tabular}

*TNM stage was based on the clinical staging system of ocular adnexal lymphoma proposed by the American Joint Committee on Cancer. ECOG; Eastern Cooperative Oncology Group.

(PR). At one month after the treatment, 28 patients (84.8\%) were in CR and five patients $(15.2 \%)$ in PR. On follow up, 31 patients $(93.9 \%)$ had achieved CR at best and two $(6.1 \%)$ remained in PR. The median time to CR was 4.1 months (range, 1.7-17.7 months) after initiation of treatment in patients who achieved CR. Because the study population was small and the $\mathrm{CR}$ rate was high, no significant predictors of best response were identified by statistical analysis.

The median duration of follow-up was 50.6 months (range, 7.4-62.8 months). The cumulative CR rate was $93.9 \%$ at 2 years. The cumulative $\mathrm{CR}$ rate in patients who had conjunctiva-confined disease $(\mathrm{T}=1)$ was significantly higher than that in patients who had disease spreading 
Table 2: Response to R-CVP in limited stage ocular adnexal MALT lymphoma patients with bilateral or extra-conjunctival involvement

\begin{tabular}{lccc}
\hline & $\begin{array}{c}\text { 1 month after the } \\
\text { completion of treatment }\end{array}$ & $\begin{array}{c}\text { Best response during } \\
\text { follow up }\end{array}$ & Last follow up \\
\hline $\mathrm{CR}$ & $28(84.8 \%)$ & $31(93.9 \%)$ & $30(90.9 \%)$ \\
$\mathrm{PR}$ & $5(15.2 \%)$ & $2(6.1 \%)$ & $2(6.1 \%)$ \\
$\mathrm{NR}$ & $0(0 \%)$ & $0(0 \%)$ & $0(0 \%)$ \\
Progression & $0(0 \%)$ & $0(0 \%)$ & $3(9.1 \%)^{*}$ \\
\hline
\end{tabular}

*Three patients relapsed 22.5, 35.1 and 37.4 months of treatment, respectively. CR: complete response; PR: partial response; NR: no response; LDH: lactic dehydrogenase; IPI: international prognostic index.

beyond the conjunctiva $(\mathrm{T}>1)(100 \%$ vs. $91.3 \% ; \mathrm{P}=$ 0.022 , Figure 1). Patients under 49 years of age had higher CR rates than patients over 49 years of age $(100 \%$ vs. $90.4 \% ; \mathrm{P}=0.034)$. The involvement of areas beyond the conjunctiva $(\mathrm{T}>1)$ was the only independent factor for $\mathrm{CR}$ acquisition by the multivariate analysis (hazard ratio [HR] $0.424, \mathrm{P}=0.044)$.

\section{Progression-free and overall survival}

Among the study patients, three patients relapsed at 22.5, 35.1, and 37.4 month after initiation of treatment whose TNM stage was bT1, T2a, and T2d, respectively. All the three patients relapsed at the same location in the eye and thus received localized radiotherapy as a second line treatment. They were currently in $\mathrm{CR}$ at last follow-up. No study patient showed distant relapse during follow up. The estimated PFS at 4 years was 90.3 $\pm 5.3 \%$ (Figure 2 ). None of the study patients died until the last observation, and overall survival (OS) was $100 \%$.
No significant prognostic factors for OS and PFS were identified by the statistical analysis.

\section{Toxicity}

The treatment-related toxicities are listed in Table 3. All study patients completed the treatment following the planned doses without dose reduction. The common frequent side effects of this regimen were neutropenia and peripheral neuropathy. Four patients experienced grade 3 or 4 neutropenia and two patients had grade 3 or 4 hepatotoxicity. No patient underwent cataract surgery and had secondary malignancy until last day of follow-up.

\section{DISCUSSION}

Previous series showed that $7-22 \%$ of OAML patients have bilaterality and $29-73 \%$ of OAML patients have non-conjunctival disease [8]. We thought that these
A

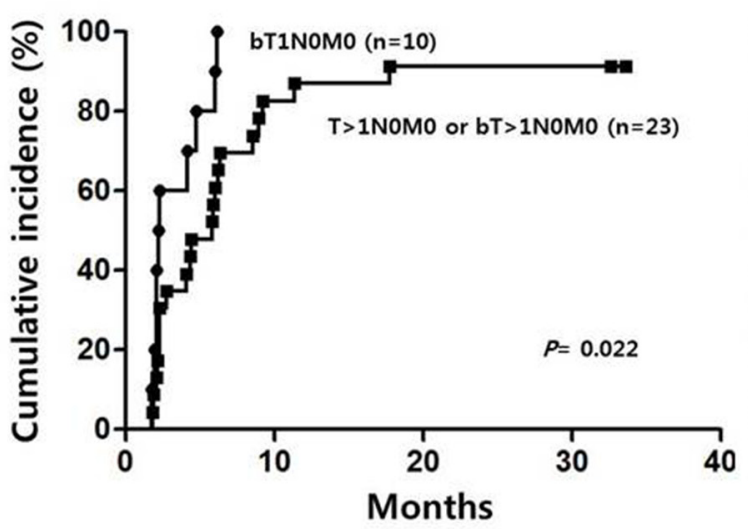

B

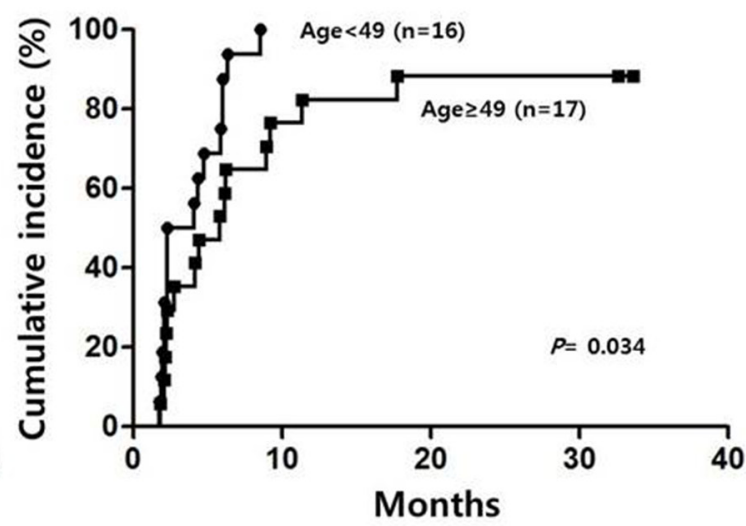

Figure 1: Cumulative incidence of complete response in the study patients according to TNM group (A) and age group (B), assessed by univariate analysis. 
patients would benefit most from this phase II study because this group of patients has a higher risk of relapse and radiation related complications after radiotherapy. The overall response rate to R-CVP treatment for limitedstage OAML with these adverse factors was $100 \%$, with CR of $84.8 \%$. The overall CR rate reached $93.9 \%$ at 2 years and the PFS was $90.3 \%$ at 4 years. Of note, all relapse sites were at the original locations and distant relapse was not observed in any of our study patients. Previous studies using radiotherapy have demonstrated that the disease recurred predominantly in non-irradiated contralateral and distant areas but we did not observe distant recurrence in our study patients, which suggests that systemic chemoimmunotherapy may reduce the risk of distant recurrence.

Because prior trials using either rituximab or cytotoxic agents alone for MALT lymphoma had not shown satisfactory results $[17,18,23]$, recent studies have evaluated combination regimens consisting of rituximab plus cytotoxic chemotherapeutic agents for the treatment of patients with various sites and stages I-IV of MALT lymphoma and shown promising results $[15,16,20]$. A previous phase II study, MALT2008-01, using rituximab plus bendamustine in patients with MALT lymphoma reported a CR rate of $100 \%$ and a 4 -year PFS of $91 \%$ in non-gastric disease. Another previous phase III study, IELSG-19, using rituximab plus chlorambucil for extranodal marginal zone B cell lymphoma reported a CR rate of $78 \%$ and 5 -year PFS of $71 \%[15,16]$. Although direct comparison with other chemoimmunotherapy including rituximab is difficult because of heterogeneity of the prior study patients including gastric MALT lymphoma and stage III-IV disease patients, the present trial suggested $\mathrm{R}-\mathrm{CVP}$ regimen has comparable treatment outcomes to those for other chemoimmunotherapy regimens. However, many previous reports suggested that MALT lymphoma might progress a long time after achieving $\mathrm{CR}$ or $\mathrm{PR}$ with radiotherapy or systemic therapy $[1,11,12,16]$ and thus we need further follow up to confirm an excellent longterm PFS in this group of patients when they are treated with R-CVP or other chemoimmunotherapy.

The overall response rate and OS in this study was $100 \%$ and three patients relapsed; hence, predictors of response, OS, and PFS were not identifiable by statistical analysis but a predictor for cumulative $\mathrm{CR}$ achievement was identified. The patients with disease involving structures beyond conjunctivae $(\mathrm{T}>1)$ showed a lower cumulative $\mathrm{CR}$ rate, even after adjusting for other potential prognostic factors. Ocular adnexal lymphoma is generally staged using the Ann Arbor staging system as other lymphoma, but this system is not perfect for this disease because most patients with this disease have limited stage and the bilaterality, nonconjunctival location, and nodal involvement are related to a worse prognosis in limitedstage patients [8]. Our previous study also suggested that the treatment outcome of OAML can be influenced by the TNM stage when the disease is treated by radiotherapy [6]. The present study also suggests that the TNM stage could have an independent impact on CR achievement in patients with limited-stage disease according to the Ann Arbor staging system, even when they are treated with systemic chemoimmunotherapy. Older age was likely to be another unfavorable predictor for $\mathrm{CR}$ achievement, with borderline significance $(P=0.062)$. Because we could not identify any prognostic factors for PFS, including TNM stage, further follow up is required to clarify whether $\mathrm{T}>1$ by the TNM staging system can be associated with lower PFS.

The R-CVP regimen is a widely used treatment for lymphoma and the toxicities in the present study were as observed in previous studies [24]. We did not observe any ophthalmic complications, which demonstrated that
A

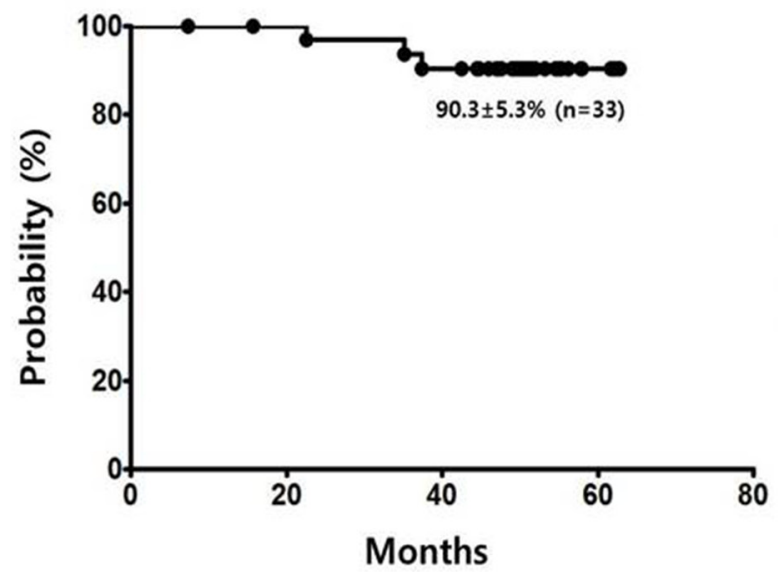

B

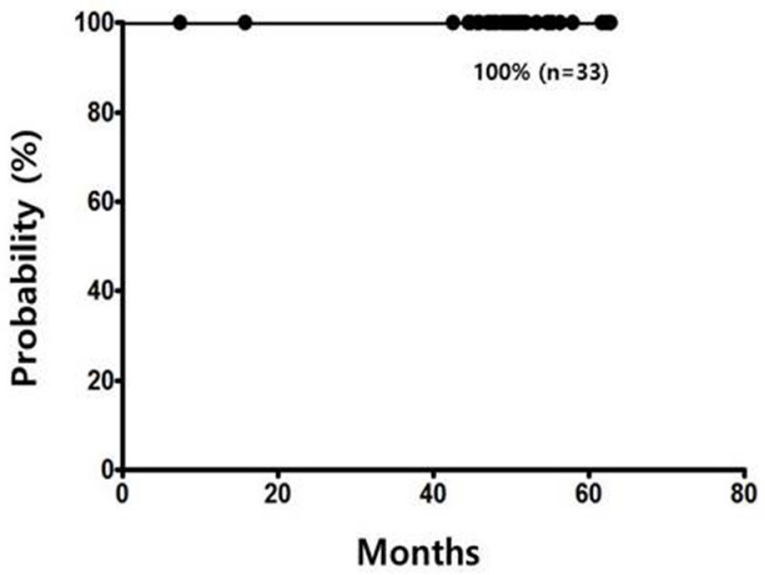

Figure 2: Progression-free survival (A) and overall survival (B) of limited stage ocular adnexal MALT lymphoma patients with bilateral or beyond-conjunctival involvement treated with R-CVP. 
Table 3: Toxicity

\begin{tabular}{lcc}
\hline Toxicity & Any grade & Grade 3 or 4 \\
\hline Anemia & $6(19 \%)$ & $0(0 \%)$ \\
Neutropenia & $11(33 \%)$ & $4(12 \%)$ \\
Paresthesia & $11(33 \%)$ & $0(0 \%)$ \\
Hepatotoxicity & $7(21 \%)$ & $2(6 \%)$ \\
Constipation & $4(12 \%)$ & $0(0 \%)$ \\
Hyperglycemia & $3(9 \%)$ & $1(3 \%)$ \\
\hline
\end{tabular}

R-CVP can avoid the radiotherapy-related ophthalmic complications. This finding was consistent with the previous retrospective studies, in which patients treated with chemotherapy alone showed few of the ophthalmic complications that were frequently seen after radiotherapy $[18,23,25]$.

This phase II study demonstrated that R-CVP is a more-effective frontline regimen showing durable response for limited-stage OAML with adverse factors than is CVP. The chemoimmunotherapy can be considered as the alternative frontline therapy for limited-stage OAML patients who wish to avoid the risk of radiologic ophthalmic complications.

\section{MATERIALS AND METHODS}

\section{Patients and study design}

This single arm, open-label, multicenter, phase II clinical trial evaluated R-CVP treatment in limited-stage OAML with bilateral or beyond-conjunctival involvement. Patients with a histologically confirmed extranodal marginal zone B-cell lymphoma of MALT from the ocular adnexa were included.

The enrolment criteria for disease status were Ann Arbor stage I-II OAML with adverse factors; bilateral or beyond-conjunctival involvement, which is bT1 or $\mathrm{T}>1$, N0, and M0 based on the TNM staging system for ocular adnexal lymphoma proposed by the American Joint Committee on Cancer. Measurable disease at baseline was defined as at least one lesion that was accurately measurable. Patients were required to be $\geq 18$ years old, with Eastern Cooperative Oncology Group (ECOG) performance scores of $0-2$, with no prior chemotherapy or radiation therapy, and with adequate bone marrow, renal and hepatic function. Exclusions were made for disease confined to unilateral conjunctiva (T1N0M0) or Ann Arbor stage III-IV disease. In this study, bilateral disease without involvement of any other organ was considered as stage IE rather than stage IVE.

The protocol was approved by the Institutional Review Boards of all participating institutions and all patients provided written informed consent at the time of enrolment. We described the study to consecutive patients who were eligible for this study, and if the patients agreed to participate in this study, we enrolled them.

\section{Treatment}

Patients were treated every 21 days with six cycles of rituximab $\left(375 \mathrm{mg} / \mathrm{m}^{2}\right)$, cyclophosphamide $(750 \mathrm{mg} /$ $\mathrm{m}^{2}$ ), and vincristine $\left(1.4 \mathrm{mg} / \mathrm{m}^{2}\right)$ on day 1 and prednisolone $\left(60 \mathrm{mg} / \mathrm{m}^{2}\right)$ on days $1-5$, which was followed by 2 cycles of rituximab $\left(375 \mathrm{mg} / \mathrm{m}^{2}\right)$ every 21 days. Dose adjustment was permitted based on hematologic toxicity, neurologic toxicity, and infusion reactions. For hematologic toxicity, the use of granulocyte colony-stimulating factor was allowed.

\section{Study end points and assessments}

The primary end point of the study was the CR rate based on the revised response criteria for malignant lymphoma [26]. The secondary end point was PFS and OS.

For the evaluation of efficacy, a contrast-enhanced magnetic resonance imaging (MRI) scan and ophthalmic examination were performed at baseline, within four weeks of the start of treatment. Subsequently, the same imaging study and ophthalmic exam were repeated for response assessment after the third and sixth cycles of R-CVP and after completion of all planned treatments. Follow-up reassessments were conducted every 3 months during the first 2 years and every 6 months thereafter. We did not recommend routine follow-up bone marrow study for this limited-stage disease except at the initial baseline work up. Follow-up bone marrow biopsy was planned only when the disease progressed or relapsed. Treatmentrelated toxicities were evaluated using the Common Terminology Criteria for Adverse Events (CTCAE 4.0).

\section{Statistical considerations}

A single-stage design was used to evaluate the efficacy of the regimen. A CR rate of $\geq 87 \%$ among patients at the end of the study was considered superior 
to that for the CVP regimen. The target rates were based on the study by Song et al. which showed a $67 \%$ CR rate to CVP in patients with limited-stage bilateral or beyondconjunctival OAML [18]. We thus needed 29 evaluable patients with a one-sided type I error of 5\% and $80 \%$ power for a single-stage design $[27,28]$. Anticipating a $10 \%$ drop-out rate, we enrolled 33 patients.

PFS was defined as the time from entry onto this study until lymphoma progression or death as a result of any cause. OS was defined as the time from entry onto this study until death as a result of any cause and censored at the date of the last follow-up visit [26]. Time to CR was defined as the time from the date of treatment initiation to the date of documented CR. The cumulative incidence of CR was calculated using time to $\mathrm{CR}$. Cox regression hazard analysis was used for multivariate analysis of survival outcomes and the cumulative incidence of CR achievement. A 2 -sided $P$ value $<0.05$ was considered significant.

\section{Author contributions}

SG Cho, SWo Yang, WS Lee, JW Yang, SY Oh, HB Ahn, DH Yang, SK Park, JH Chang, HJ Kim, and MJ Lee enrolled and treated the study patients; SY Kim, SW Yang, and WS Lee acquired and analyzed data; SY Kim interpreted data and wrote the manuscript; SG Cho conceptualized the idea and designed this study; and all authors read and approved the final manuscript. SY Kim, SW Yang, and WS Lee contributed equally to this work.

\section{ACKNOWLEDGMENTS}

The authors thank all the investigators who enrolled patients in this phase II study and the patients who participated in the study.

\section{CONFLICTS OF INTEREST}

We have no conflicts of interest to declare.

\section{FUNDING}

Roche Pharmaceuticals provided rituximab but had no other role in this study.

\section{REFERENCES}

1. Yoon JS, Ma KT, Kim SJ, Kook K, Lee SY. Prognosis for patients in a Korean population with ocular adnexal lymphoproliferative lesions. Ophthal Plast Reconstr Surg. 2007; 23: 94-9. https://doi.org/10.1097/IOP.0b013e3180 30b05800002341-200703000-00003.

2. Cho EY, Han JJ, Ree HJ, Ko YH, Kang YK, Ahn HS, Ahn SD, Park CJ, Huh J. Clinicopathologic analysis of ocular adnexal lymphomas: extranodal marginal zone b-cell lymphoma constitutes the vast majority of ocular lymphomas among Koreans and affects younger patients. Am J Hematol. 2003; 73: 87-96.

3. Woo JM, Tang CK, Rho MS, Lee JH, Kwon HC, Ahn HB. The clinical characteristics and treatment results of ocular adnexal lymphoma. Korean J Ophthalmol. 2006; 20: 7-12.

4. Fung CY, Tarbell NJ, Lucarelli MJ, Goldberg SI, Linggood RM, Harris NL, Ferry JA. Ocular adnexal lymphoma: clinical behavior of distinct World Health Organization classification subtypes. Int J Radiat Oncol Biol Phys. 2003; 57: 1382-91. https://doi.org/S0360301603007673.

5. Nam H, Ahn YC, Kim YD, Ko Y, Kim WS. Prognostic significance of anatomic subsites: results of radiation therapy for 66 patients with localized orbital marginal zone B cell lymphoma. Radiother Oncol. 2009; 90: 236-41.

6. Lee SE, Paik JS, Cho WK, Choi BO, Lee SN, Jung SE, Park KS, Kang CS, Kim SH, Yang SW, Cho SG. Feasibility of the TNM-based staging system of ocular adnexal extranodal marginal zone lymphoma of mucosa-associated lymphoid tissue (MALT lymphoma). Am J Hematol. 2011; 86: 262-6. https://doi.org/10.1002/ajh.21963.

7. Uno T, Isobe K, Shikama N, Nishikawa A, Oguchi M, Ueno $\mathrm{N}$, Itami J, Ohnishi H, Mikata A, Ito H. Radiotherapy for extranodal, marginal zone, B-cell lymphoma of mucosaassociated lymphoid tissue originating in the ocular adnexa: a multiinstitutional, retrospective review of 50 patients. Cancer. 2003; 98: 865-71.

8. Stefanovic A, Lossos IS. Extranodal marginal zone lymphoma of the ocular adnexa. Blood. 2009; 114: 501-10.

9. Lee SW, Suh CO, Kim GE, Yang WI, Lee SY, Hahn JS, Park JO. Role of radiotherapy for primary orbital lymphoma. Am J Clin Oncol. 2002; 25: 261-5.

10. Martinet S, Ozsahin M, Belkacemi Y, Landmann C, Poortmans P, Oehlere C, Scandolaro L, Krengli M, Maingon P, Miralbell R, Studer G, Chauvet B, Marnitz S, et al. Outcome and prognostic factors in orbital lymphoma: a Rare Cancer Network study on 90 consecutive patients treated with radiotherapy. Int J Radiat Oncol Biol Phys. 2003; 55: 892-8.

11. Raderer M, Streubel B, Woehrer S, Puespoek A, Jaeger U, Formanek M, Chott A. High relapse rate in patients with MALT lymphoma warrants lifelong follow-up. Clin Cancer Res. 2005; 11: 3349-52.

12. Ejima Y, Sasaki R, Okamoto Y, Maruta T, Azumi A, Hayashi Y, Demizu Y, Ota Y, Soejima T, Sugimura K. Ocular adnexal mucosa-associated lymphoid tissue lymphoma treated with radiotherapy. Radiother Oncol. 2006; 78: 6-9.

13. Woolf DK, Kuhan H, Shoffren O, Akinnawo EM, Sivagurunathan B, Boyce H, Plowman PN. Outcomes of primary lymphoma of the ocular adnexa (orbital lymphoma) treated with radiotherapy. Clin Oncol (R Coll Radiol). 2015; 27: 153-9. https://doi.org/10.1016/j.clon.2014.10.0 02S0936-6555(14)00376-8. 
14. Harada K, Murakami N, Kitaguchi M, Sekii S, Takahashi K, Yoshio K, Inaba K, Morota M, Ito Y, Sumi M, Suzuki $\mathrm{S}$, Tobinai $\mathrm{K}$, Uno $\mathrm{T}$, et al. Localized ocular adnexal mucosa-associated lymphoid tissue lymphoma treated with radiation therapy: a long-term outcome in 86 patients with 104 treated eyes. Int J Radiat Oncol Biol Phys. 2014; 88: 650-4. https://doi.org/10.1016/j.ijrobp.2013.11.2 35S0360-3016(13)03596-7.

15. Salar A, Domingo-Domenech E, Panizo C, Nicolás C, Bargay J, Muntañola A, Canales M, Bello LJ. First-line response-adapted treatment with the combination of bendamustine and rituximab in patients with mucosaassociated lymphoid tissue lymphoma (MALT2008-01): a multicentre, single-arm, phase 2 trial. Lancet Haematol. 2014; 1: e104-e11.

16. Zucca E, Conconi A, Laszlo D, Lopez-Guillermo A, Bouabdallah R, Coiffier B, Sebban C, Jardin F, Vitolo U, Morschhauser F, Pileri SA, Copie-Bergman C, Campo $\mathrm{E}$, et al. Addition of rituximab to chlorambucil produces superior event-free survival in the treatment of patients with extranodal marginal-zone B-cell lymphoma: 5-year analysis of the IELSG-19 Randomized Study. J Clin Oncol. 2013; 31: 565-72. https://doi.org/10.1200/JCO.2011.40.62 72JCO.2011.40.6272.

17. Ferreri AJ, Ponzoni M, Martinelli G, Muti G, Guidoboni M, Dolcetti R, Doglioni C. Rituximab in patients with mucosalassociated lymphoid tissue-type lymphoma of the ocular adnexa. Haematologica. 2005; 90: 1578-9.

18. Song EK, Kim SY, Kim TM, Lee KW, Yun T, Na II, Shin H, Lee SH, Kim DW, Khwarg SI, Heo DS. Efficacy of chemotherapy as a first-line treatment in ocular adnexal extranodal marginal zone B-cell lymphoma. Ann Oncol. 2008; 19: 242-6.

19. Levy M, Copie-Bergman C, Amiot A, Dupuis J, Le Baleur Y, Belhadj K, Hemery F, Sobhani I, Delfau-Larue MH, Leroy K, Haioun C, Delchier JC. Rituximab and chlorambucil versus rituximab alone in gastric mucosaassociated lymphoid tissue lymphoma according to $\mathrm{t}(11 ; 18)$ status: a monocentric non-randomized observational study. Leuk Lymphoma. 2013; 54: 940-4. https://doi.org/10.3109/ 10428194.2012.729832.

20. Kiesewetter B, Mayerhoefer ME, Lukas J, Zielinski CC, Mullauer L, Raderer M. Rituximab plus bendamustine is active in pretreated patients with extragastric marginal zone B cell lymphoma of the mucosa-associated lymphoid tissue (MALT lymphoma). Ann Hematol. 2014; 93: 249-53. https://doi.org/10.1007/s00277-013-1865-3.

21. Kang HJ, Kim WS, Kim SJ, Lee JJ, Yang DH, Kim JS, Lee SR, Lee GW, Kim HJ, Kim HY, Oh SY, Kim HC, Eom $\mathrm{HS}$, et al. Phase II trial of rituximab plus CVP combination chemotherapy for advanced stage marginal zone lymphoma as a first-line therapy: Consortium for Improving Survival of Lymphoma (CISL) study. Ann Hematol. 2012; 91: 54351. https://doi.org/10.1007/s00277-011-1337-6.

22. Coupland SE, White VA, Rootman J, Damato B, Finger PT. A TNM-based clinical staging system of ocular adnexal lymphomas. Arch Pathol Lab Med. 2009; 133: 1262-7.

23. Ben Simon GJ, Cheung N, McKelvie P, Fox R, McNab AA. Oral chlorambucil for extranodal, marginal zone, B-cell lymphoma of mucosa-associated lymphoid tissue of the orbit. Ophthalmology. 2006; 113: 1209-13. https://oi.org/ S0161-6420(06)00155-2.

24. Marcus R, Imrie K, Belch A, Cunningham D, Flores E, Catalano J, Solal-Celigny P, Offner F, Walewski J, Raposo J, Jack A, Smith P. CVP chemotherapy plus rituximab compared with CVP as first-line treatment for advanced follicular lymphoma. Blood. 2005; 105: 1417-23. https:// doi.org/2004-08-3175.

25. Paik JS, Cho WK, Lee SE, Choi BO, Jung SE, Park GS, Kim SH, Yang SW, Cho SG. Ophthalmologic outcomes after chemotherapy and/or radiotherapy in non-conjunctival ocular adnexal MALT lymphoma. Ann Hematol. 2012; 91: 1393-401. https://doi.org/10.1007/s00277-012-1469-3.

26. Cheson BD, Pfistner B, Juweid ME, Gascoyne RD, Specht L, Horning SJ, Coiffier B, Fisher RI, Hagenbeek A, Zucca E, Rosen ST, Stroobants S, Lister TA, et al. Revised response criteria for malignant lymphoma. J Clin Oncol. 2007; 25: 579-86. https://doi.org/10.1007/s00277-012-1469-3.

27. Fleming TR. One-sample multiple testing procedure for phase II clinical trials. Biometrics. 1982; 38: 143-51.

28. A'Hern RP. Sample size tables for exact single-stage phase II designs. Stat Med. 2001; 20: 859-66. https://doi. org/10.1002/sim.721. 